\title{
Assessment of Projected Temperature Over West Africa Using CORDEX Regional Climate Models
}

\author{
Ifeka Adolphus* Balogun Ifeoluwa A. Akinbobola Ademola \\ Department of Meteorology and Climate Science, Federal University of Technology Akure, Nigeria \\ ${ }^{*}$ Corresponding Author: adolphusifeka@yahoo.com
}

\begin{abstract}
This study assessed the projections of temperature over West Africa using the simulated daily temperatures which were output of two (2) Coordinated Regional Climate Downscaling Experiment (CORDEX) models, include historical runs (1951-2005) and two (2) concentration pathways scenarios (RCP 4.5 from 2006-2100 and RCP 8.5 from 2006-2070) obtained from Earth System Grid Federation (ESGF) and Copernicus Climate Change Service (C3S-Climate Data Store) with spatial resolution of $0.22^{\circ}$. Results show that over West Africa under the Representation Concentration Pathways (RCP 4.5) scenario, there is a strong agreement between the distribution of model and observed PDF for the maximum temperature as the probability density functions ( PDF) increases between 0.1 to 0.2 within the range of maximum temperature of $32.5^{\circ} \mathrm{C}$ to $36.0^{\circ} \mathrm{C}$, the observed and MPI-CCLM5 revealed an agreement while the CCCma-CanRCM4 overestimated the PDF with a spike of 0.45 in March, April and May from 1979-2018. The validation of the PDF yielded skill score for the maximum temperature revealed at 0.86 and 0.81 for CCCma-CanRCM4 and MPI-CCLM5 models respectively under RCP 4.5 scenario in March, April and May from 1979-2018 over West Africa. In June, July, August and September from 1979 to 2018 under the RCP 4.5 scenario, there is a fair agreement between the distribution of model and observed PDF for the maximum temperature as the PDF increases from 0.1 to 0.15 with the MPI-CCLM5 model in fair agreement with the observed while the CCCma-CanRCM4 model overestimated the observed with a spike PDF value of 0.47.The validation of the PDF yielded skill score for the maximum temperature revealed at 0.89 and 0.86 for CCCmaCanRCM4 and MPI-CCLM5 models respectively under RCP 4.5 scenario in June, July, August and September from 1979-2018 over West Africa. The findings revealed a warming trend in the possible future climate of West Africa and the temperature increase could pose a serious threat on socioeconomic activities, which necessitates a call to action for possible climate adaption and mitigation pathways for planners and policymakers.
\end{abstract}

Keywords:Temperature, RCP, PDF

DOI: $10.7176 / \mathrm{JEES} / 11-10-01$

Publication date:October $31^{\text {st }} 2021$

\section{Introduction}

Alexander et al. (2006) and New et al. (2006) revealed a significant increase, at regional level, in the temperatures of both warmest and coldest days, and in the duration and frequency of warm spells especially in South and West Africa. Donat et al. (2013) reported a global analysis of climate extreme indices based on station data since the beginning of the twentieth century: although the station density over Africa is very scarce, significant trends in the number of warm days and nights and duration of warm spells are reported for e.g. South Africa. Based on the same dataset and reanalysis data, a comprehensive analysis of climate extreme indices simulated by Global Circulation Models (GCMs) was presented by Sillmann et al. (2013a).

On the basis of reanalysis dataset for the period 1979-2011, Fontaine et al. (2013) reported an increased occurrence of hot days and heat waves in Northern Africa, associated to specific atmospheric anomalies over Morocco and the Western Sahara. Under global warming, the occurrence and intensity of extreme events, defined by IPCC (2012) as a value of a weather or climate variable above or below a threshold value near the upper or lower ends of the range of observed values, are expected to change, as reported by e.g. Tebaldi et al. (2006), Russo and Sterl (2011), Orlowsky and Seneviratne (2011), and Sillmann et al. (2013b).

Model evaluations reported by Collins et al. (2006), Johns et al. (2006) and Delworth et al. (2006) revealed detailed assessments of the strengths and weaknesses of some major climate models based on seasonal and annual time scales. Many other studies have assessed GCM performance using monthly to annual time-scale data (e.g. Knutti et al., 2006; Chiew et al., 2009; Mitchell, 2003; Whetton et al., 2005; Suppiah et al., 2007; Masanganise, 2010; Masanganise et al., 2013). In this paper, we evaluated CORDEX GCMs based on daily climatology. As Perkins et al. (2007) point out, an assessment of the capacity of models to simulate climate on daily time scales is valuable because climate on time scales of days has a direct impact on human health and activities. Some studies have evaluated GCMs based on the climatological mean (see Watterson, 1996; Taylor, 2001; Murphy et al., 2004; Ramirez-Villegas et al., 2013). However, studies by Alexander et al. (2006) and Dessai et al. (2005) revealed the importance of considering climate statistics other than means to evaluate model performance.

This study focused on use of probability density functions (PDFs) according to Millard (2013) to assess model performance and skill score developed by Siegert (2017) for forecast verification routines for weather and climate. 


\section{Data and methodology}

\subsection{Study locality}

The domain of the study lies within Latitude $0^{\circ} \mathrm{N}-20^{\circ} \mathrm{N}$ and Longitude $20^{\circ} \mathrm{W}-20^{\circ} \mathrm{E}$, it is bounded in the south by Atlantic Ocean, north by Sahara Desert and Cameroon highland in the east.

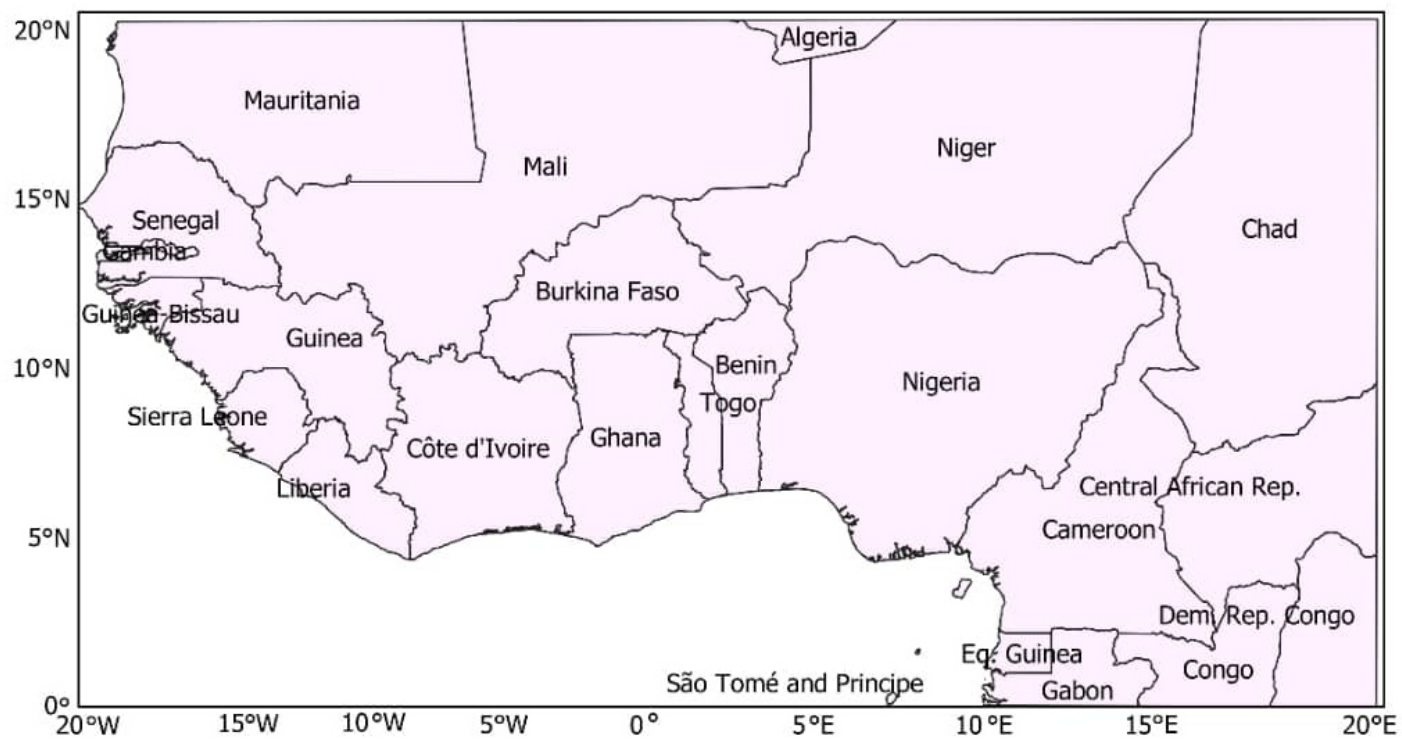

Figure 1: Map of West Africa showing the domain of study

\subsection{Methodology}

The simulated daily temperatures were output of two (2) Coordinated Regional Climate Downscaling Experiment (CORDEX) models which include historical runs (1951-2005) and two (2) concentration pathways scenarios (RCP 4.5 from 2006-2100 and RCP 8.5 from 2006-2070) obtained from Earth System Grid Federation (ESGF) and Copernicus Climate Change Service (C3S-Climate Data Store) with spatial resolution of $0.22^{0}$.

Table 1: Description of the CORDEX RCMs

\begin{tabular}{llll}
\hline Institute & Driven GCM & RCM & $\begin{array}{l}\text { RCM } \\
\text { Abbreviation }\end{array}$ \\
\hline $\begin{array}{l}\text { Canadian Centre for Climate Modelling and Analysis, } \\
\text { Canada }\end{array}$ & CCCma & CCCma- & CCCma- \\
\hline $\begin{array}{l}\text { Climate Limited-Area Modeling (CLM) Community, } \\
\text { Germany }\end{array}$ & $\begin{array}{l}\text { MPI-M-MPI- } \\
\text { ESM-LR }\end{array}$ & $\begin{array}{l}\text { CLMCOMCM- } \\
\text { CIT-CCLM5 }\end{array}$ & MPI-CCLM5 \\
\hline
\end{tabular}

Table 2: CORDEX RCMs Characteristics (Nikulian et al. 2012; Scinocca et al. 2015)

\begin{tabular}{|c|c|c|}
\hline & CCma-CanRCM4 & CLMcom-KIT-CCLM5 \\
\hline Institute & CCCma, Canada & $\begin{array}{l}\text { CLM Community,Germany } \\
\text { (https://www.clmcommunity.eu) }\end{array}$ \\
\hline Short name & CCCma & CCLM \\
\hline Projection Resolution & Rotated pole $0.22^{\circ}$ & Rotated pole $0.22^{\circ}$ \\
\hline $\begin{array}{l}\text { Vertical } \\
\text { Coordinate/Level }\end{array}$ & Hybrid Sigma-pressure & Terrain Following/3.5 \\
\hline Advection & Semi-Lagrangian Hydrostatic & $\begin{array}{l}\text { Fifth-order upwind, Baldauf and Schulz } \\
\text { (2004) }\end{array}$ \\
\hline Time step (s) & 600 seconds & 240 seconds \\
\hline Convective Scheme & $\begin{array}{l}\text { Mass flux scheme for shallow and deep } \\
\text { convection }\end{array}$ & Tiedtke (1989) \\
\hline $\begin{array}{l}\text { Turbulence Vertical } \\
\text { Diffusion }\end{array}$ & Bulk Richardson Formulation & Herzog et al. (2002), Buzzi et al. (2011) \\
\hline $\begin{array}{l}\text { Cloud Microphysics } \\
\text { Scheme }\end{array}$ & $\begin{array}{l}\text { Prognostic cloud liquid water and ice, } \\
\text { statistical cloud scheme, interactive } \\
\text { with aerosols }\end{array}$ & $\begin{array}{l}\text { Doms et al. (2007), Baldauf and Schulz } \\
\text { (2004) }\end{array}$ \\
\hline
\end{tabular}

Land Surface Scheme CLASS2.7; J. Scinocca et al. (2015) TERRA-ML; Doms et al. (2007)

Probability density function (PDF) were used to assess how the climate models reproduced the temperature 
in present climatic conditions, and also its change under climate change.

$\operatorname{Pr}[a \leq \mathrm{X} \leq b]=\int_{a}^{b} f x(x) d x$

Millard (2013) developed EnviStats on R Package and the tool was used to analyze the Probability density function. Siegert (2017) developed SpecsVerification(R-Project) for forecast verification routines for ensemble forecast of weather and climate and it was used to test the skill score of the pdf results.

Regional Climate Models' projections under Representative Concentration Pathways (RCP 4.5 and RCP 8.5) scenarios were used to evaluate future temperature over West Africa. Pyferret was used for visualization of the RCP 4.5 and RCP 8.5 respectively.

\section{Results and discussion}

\subsection{Probability Density Function and Skill Score}

\subsubsection{March, April and May}

(a) Minimum Temperature

Model and observed PDF fairly agree at the distribution as the PDF tend to increase from 0.1 to 0.5 and there is an evident agreement of the MPI-CCLM5 and the observed where the PDF value is less than 0.1. The CCCmaCanRCM4 indicated high level of deviation from the observed as the PDF value increases to 0.38 with range of the minimum temperature from $17^{\circ} \mathrm{C}$ to $25^{\circ} \mathrm{C}$ on RCP 4.5 in March, April and May over West Africa (Figure 2). The validation of the PDF yielded skill score for the minimum temperature revealed at 0.91 and 0.87 for CCCmaCanRCM4 and MPI-CCLM5 models respectively under RCP 4.5 scenario in March, April and May from 19792018 over West Africa (Figure 10).

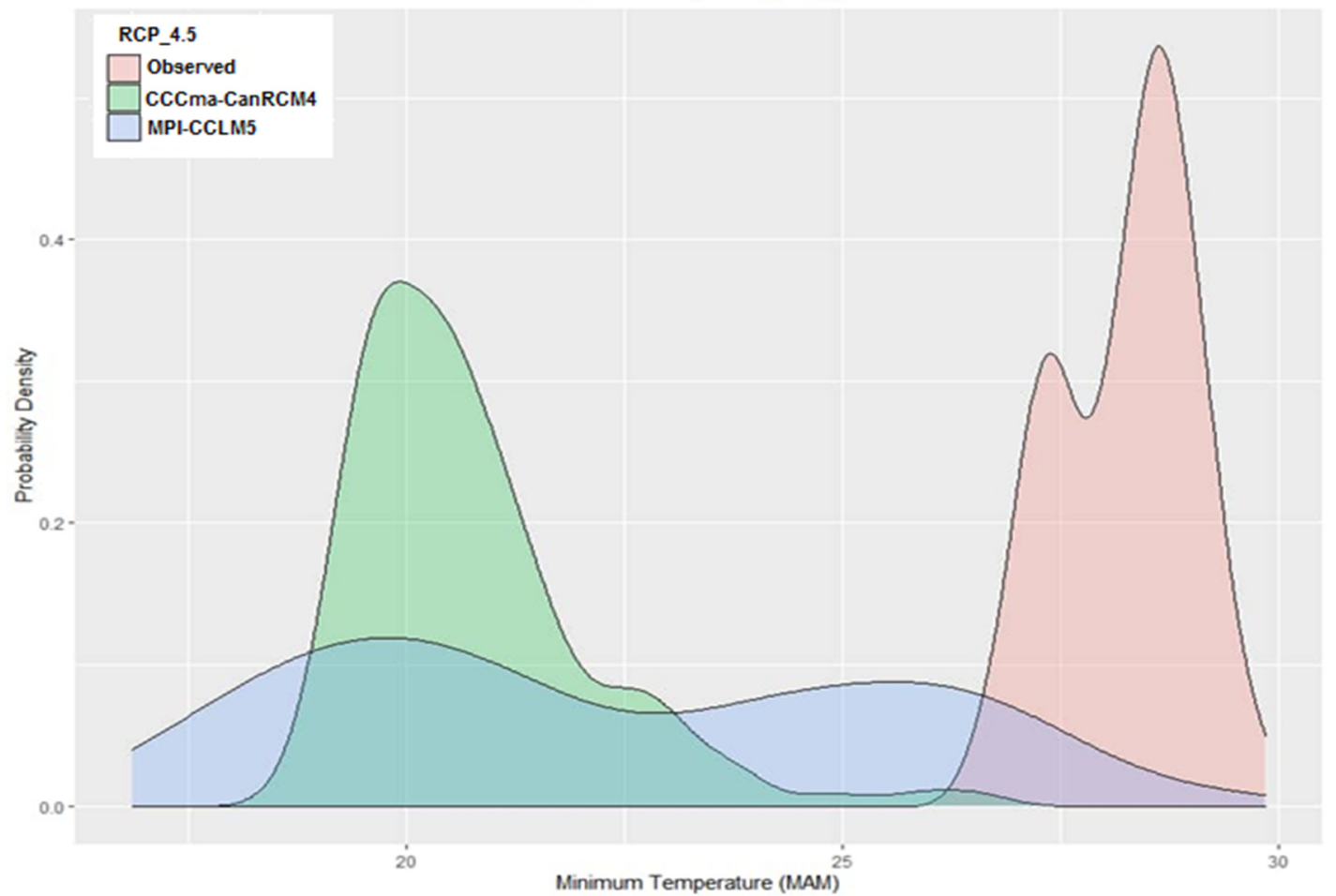

Figure 2: Probability Density Function of minimum temperature for Observed, CCCma-CanRCM4 and MPICCLM5 on RCP 4.5 in March, April and May over West Africa

Under the RCP 8.5 scenario (Figure 3), the models and observed PDF disagreed at the distribution as the PDF tend to increase from 0.1 to 0.3 with gap from the observed as the models (CCCma-CanRCM4 and MPI-CCLM5) underestimated the observed minimum temperature ranging from $17^{\circ} \mathrm{C}$ to $30^{\circ} \mathrm{C}$, although both models are in consensus in their underestimation with a spike in CCCma-CanRCM4 for PDF value ranging from 0.1-0.35 in March, April and May from 1979-2018 over West Africa. PDF yielded skill score for the minimum temperature revealed at 0.9 and 0.88 for CCCma-CanRCM4 and MPI-CCLM5 models respectively under RCP 8.5 scenario in March, April and May from 1979-2018 over West Africa. (Figure 11). 


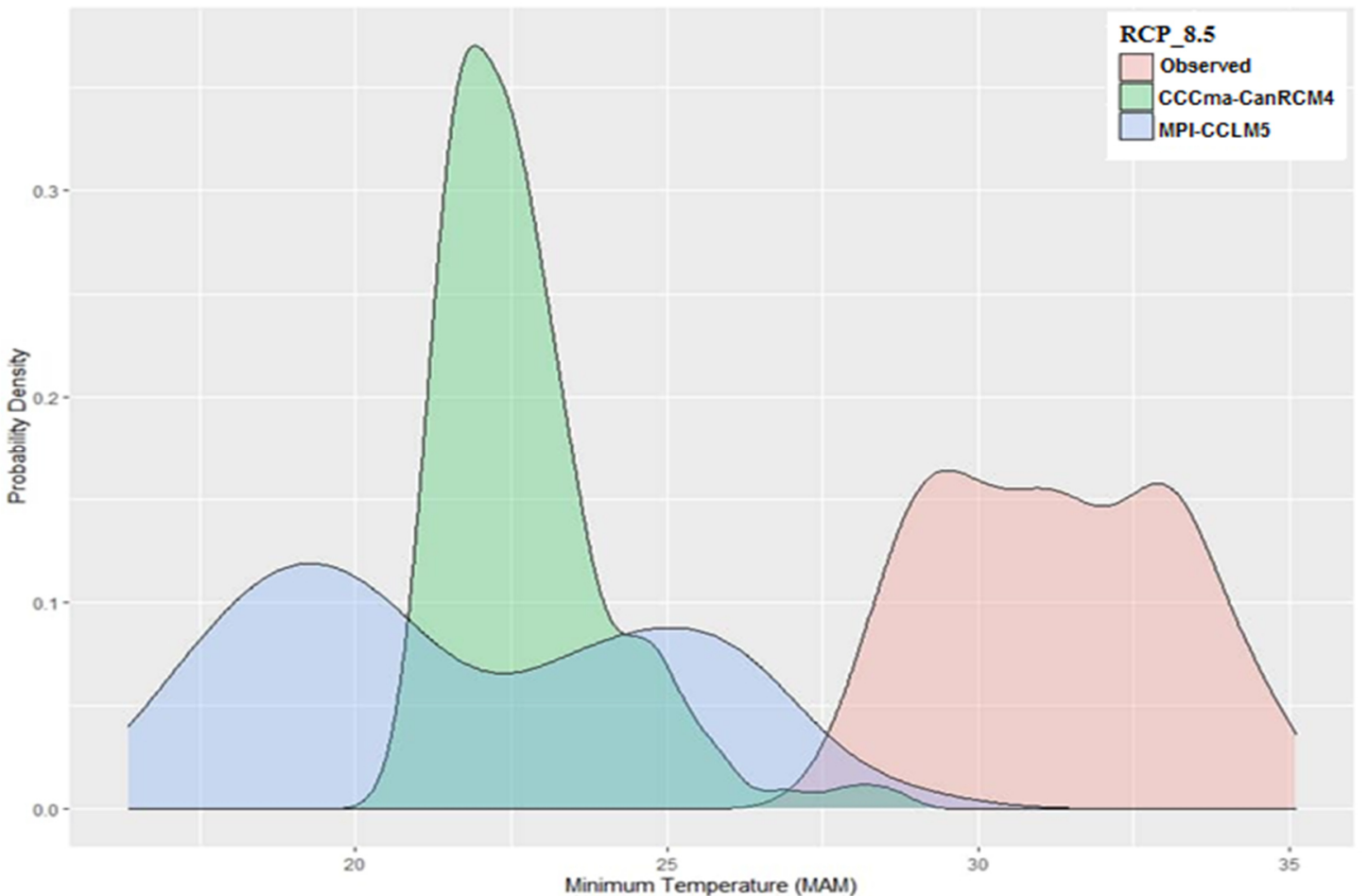

Figure 3: Probability Density Function of minimum temperature for Observed, CCCma-CanRCM4 and MPICCLM5 on RCP 8.5 in March, April and May over West Africa.

(b) Maximum Temperature

Over West Africa under the RCP 4.5 scenario, there is a strong agreement between the distribution of model and observed PDF for the maximum temperature as the PDF increases between 0.1 to 0.2 within the range of maximum temperature of $32.5^{\circ} \mathrm{C}$ to $36.0^{\circ} \mathrm{C}$ where the observed and MPI-CCLM5 revealed an agreement while the CCCmaCanRCM4 overestimated the PDF with a spike of 0.45 in March, April and May from 1979-2018 (Figure 4). The validation of the PDF yielded skill score for the maximum temperature revealed at 0.86 and 0.81 for CCCmaCanRCM4 and MPI-CCLM5 models respectively under RCP 4.5 scenario in March, April and May from 19792018 over West Africa (Figure 10).

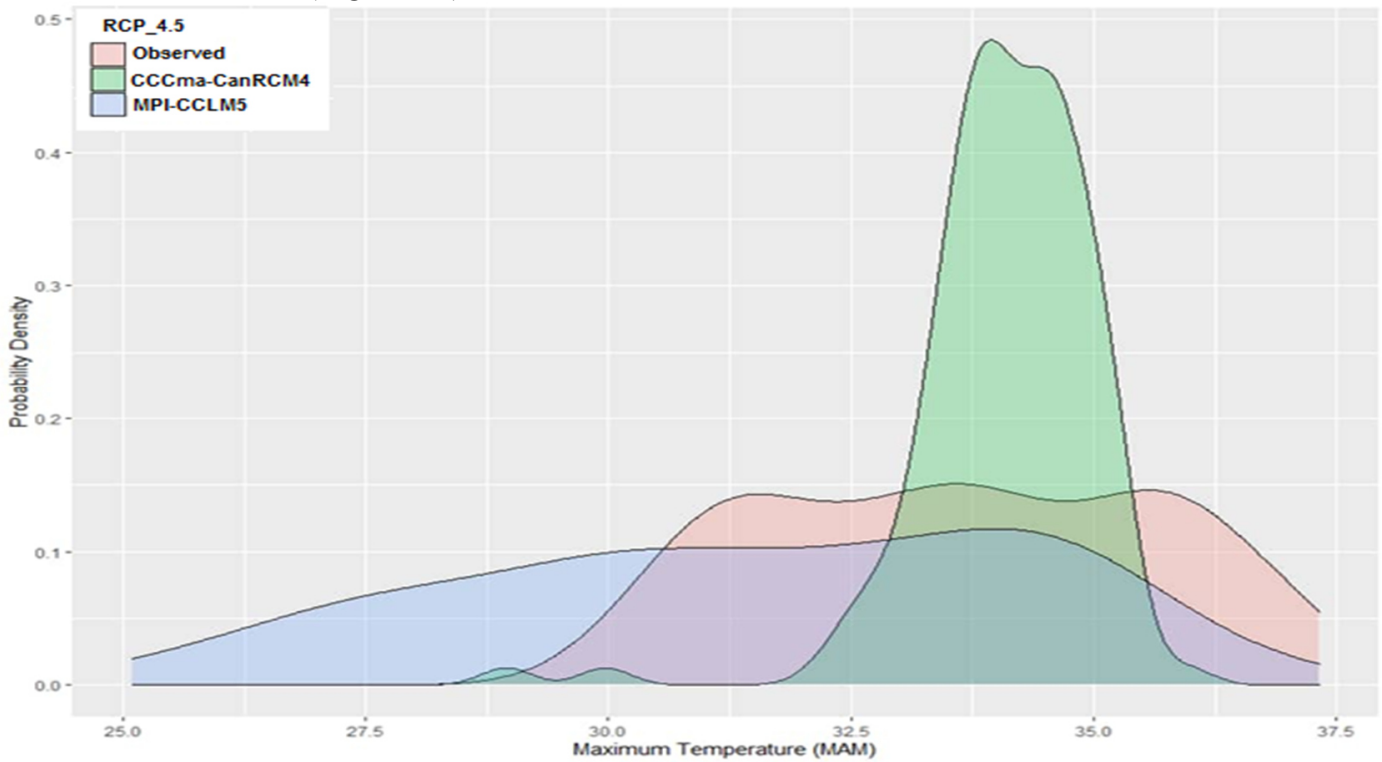

Figure 4: Probability Density Function of maximum temperature for Observed, CCCma-CanRCM4 and MPICCLM5 on RCP 4.5 in March, April and May over West Africa

Under the RCP 8.5 scenario (Figure 5), the models and observed PDF strongly agree at the distribution as the PDF tend to increase 0.1 to 0.5 within the range of maximum temperature of $33^{\circ} \mathrm{C}$ to $37^{\circ} \mathrm{C}$ while the $\mathrm{CCCma-}$ CanRCM4 overestimated with a spike in the PDF of 0.48 in March, April and May from 1979-2018 over West Africa. The PDF yielded skill score for the maximum temperature revealed at 0.87 and 0.85 for CCCma-CanRCM4 
and MPI-CCLM5 models respectively under RCP 8.5 scenario in March, April and May from 1979-2018 over West Africa (Figure 11).

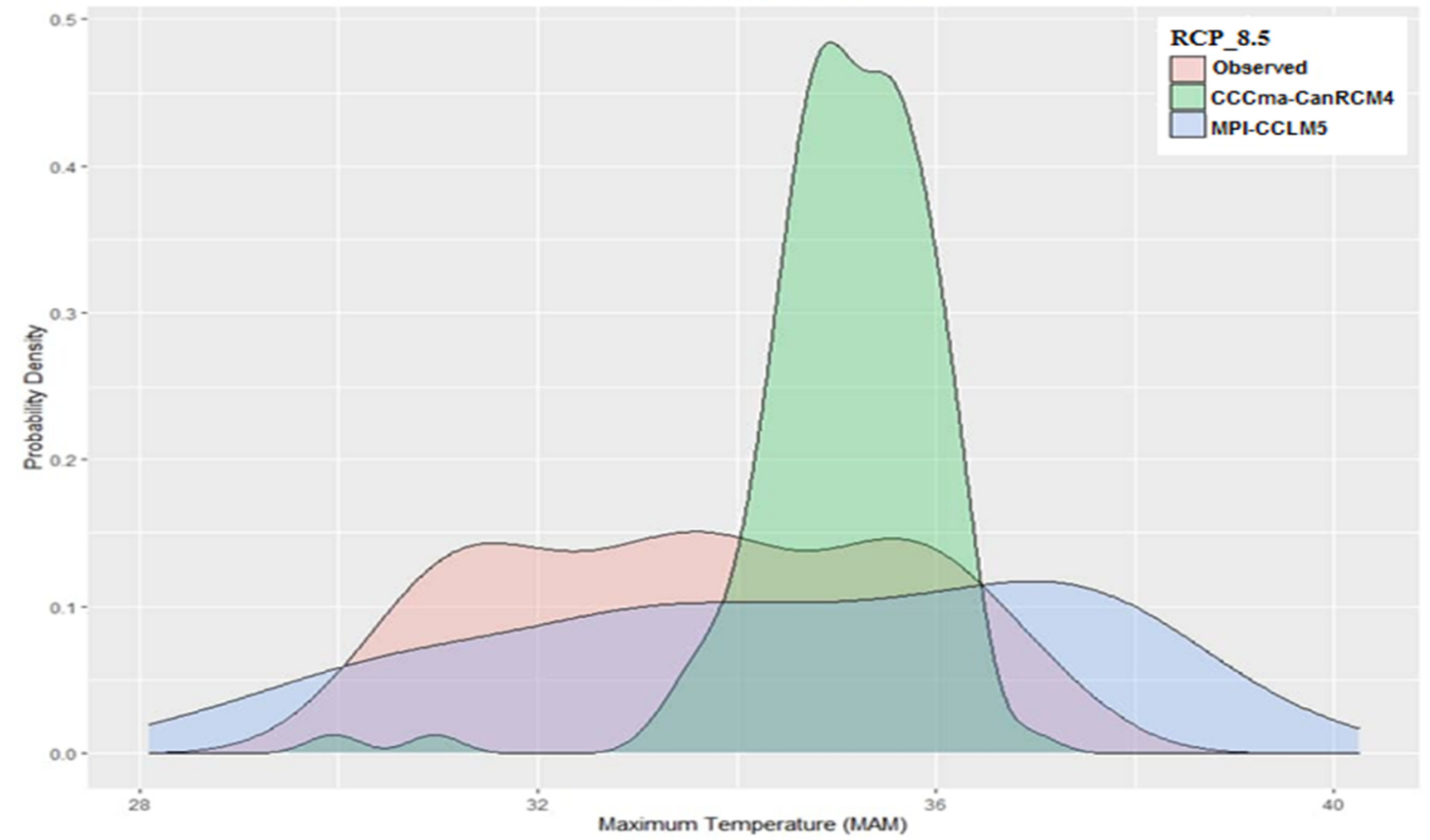

Figure 5: Probability Density Function of maximum temperature for Observed, CCCma-CanRCM4 and MPICCLM5 on RCP 8.5 in March, April and May over West Africa

\subsubsection{June, July, August and September}

(a) Minimum Temperature

Model and observed PDF strongly agree at the distribution as the PDF tend to increase from 0.1 to 0.47 and there is an evident in more agreement of the CCCma-CanRCM4 and the observed where the PDF is between 0.1 to 0.25 while the MPI-CCLM5 indicated some deviation from the observed by underestimating as the PDF of the minimum temperature as the PDF increases on RCP 4.5 in June, July, August and September over West Africa (Figure 6). The validation of the PDF yielded skill score for the minimum temperature revealed at 0.87 and 0.82 for CCCma-CanRCM4 and MPI-CCLM5 models respectively under RCP 4.5 scenario in June, July, August and September from 1979-2018 over West Africa (Figure 12).

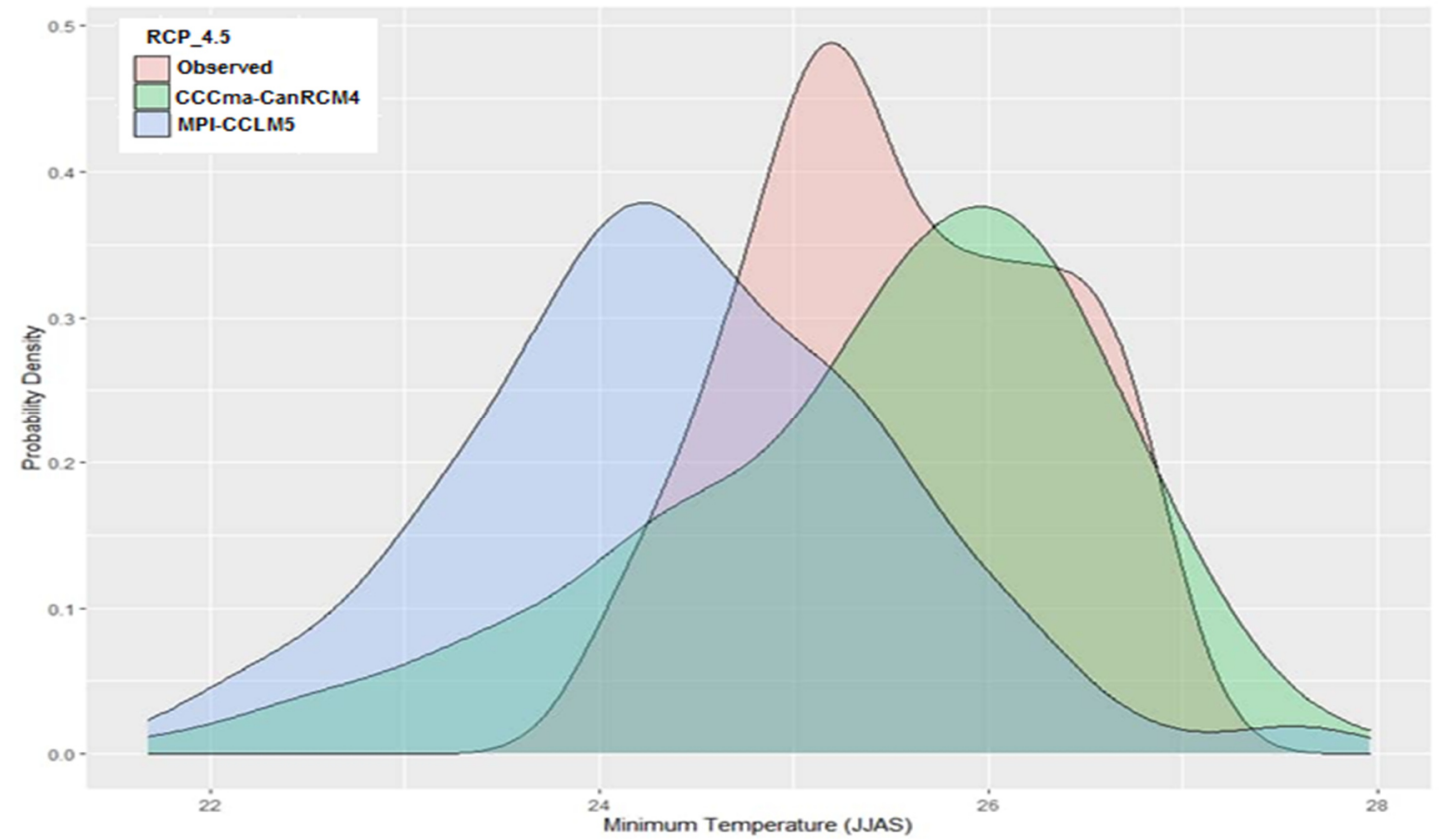

Figure 6: Probability Density Function of minimum temperature for Observed, CCCma-CanRCM4 and MPICCLM5 on RCP 4.5 in June, July, August and September over West Africa 
Under the RCP 8.5 scenario (Figure 7), the models and observed PDF fairly agree at the distribution as the PDF tend to 0.1 to 0.4 where the CCCma-CanRCM4 overestimated the PDF with minimum temperature above $30^{\circ} \mathrm{C}$ and the observed agreed with MPI-CCLM5 model revealed PDF value of 0.1 to 0.38 in June, July, August and September over West Africa. The PDF yielded skill score for the minimum temperature revealed at 0.88 and 0.84 for CCCma-CanRCM4 and MPI-CCLM5 models respectively under RCP 8.5 scenario in June, July, August and September from 1979-2018 over West Africa (Figure 13).

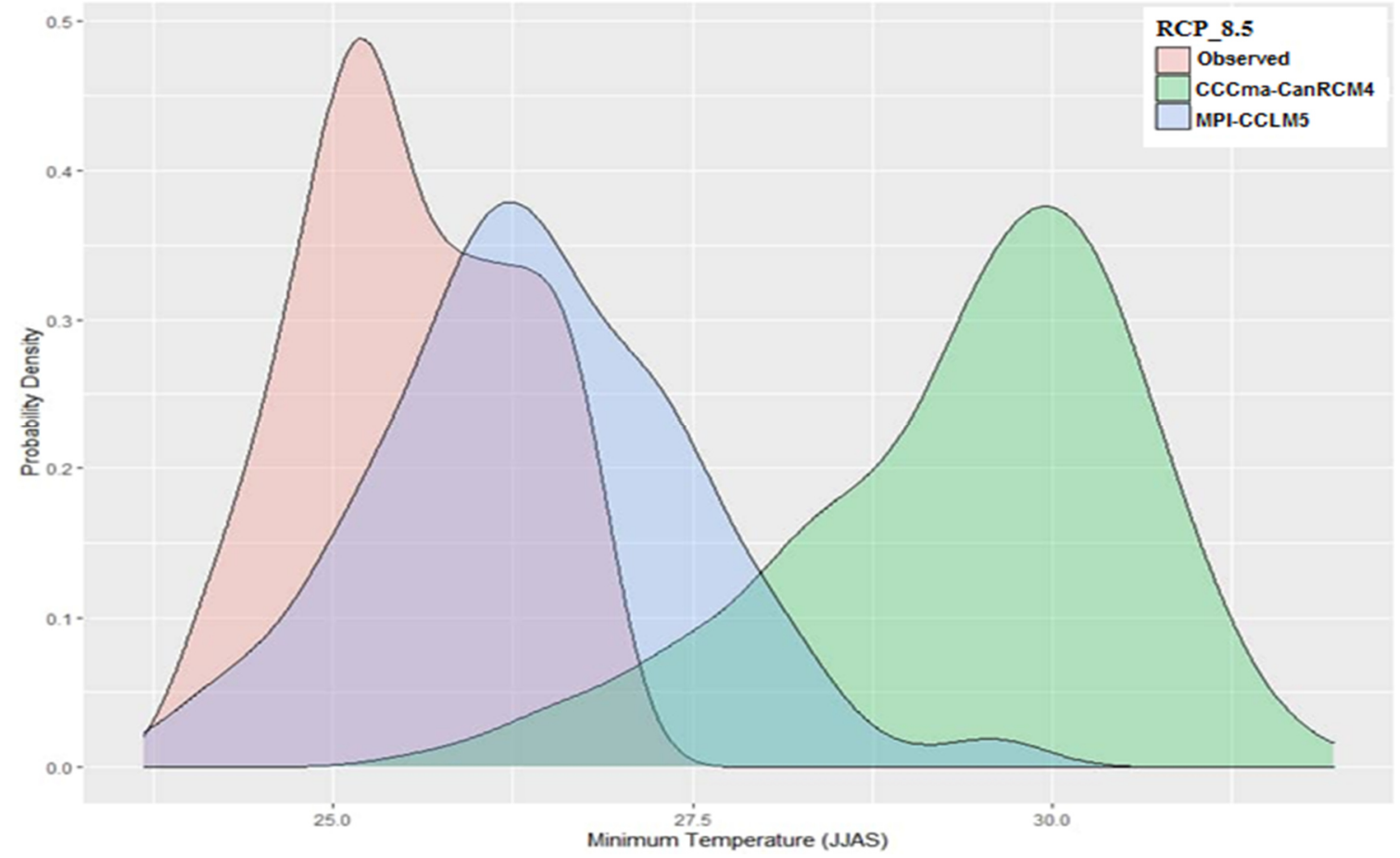

Figure 7: Probability Density Function of minimum temperature for Observed, CCCma-CanRCM4 and MPICCLM5 on RCP 8.5 in June, July, August and September over West Africa

(b) Maximum Temperature

Over West Africa under the RCP 4.5 scenario, there is a fair agreement between the distribution of model and observed PDF for the maximum temperature as the PDF increases from 0.1 to 0.15 with the MPI-CCLM5 model in fair agreement with the observed while the CCCma-CanRCM4 model overestimated the observed with a spike PDF value of 0.47 in June, July, August and September from 1979 to 2018 (Figure 8). The validation of the PDF yielded skill score for the maximum temperature revealed at 0.89 and 0.86 for CCCma-CanRCM4 and MPICCLM5 models respectively under RCP 4.5 scenario in June, July, August and September from 1979-2018 over West Africa (Figure 12). 


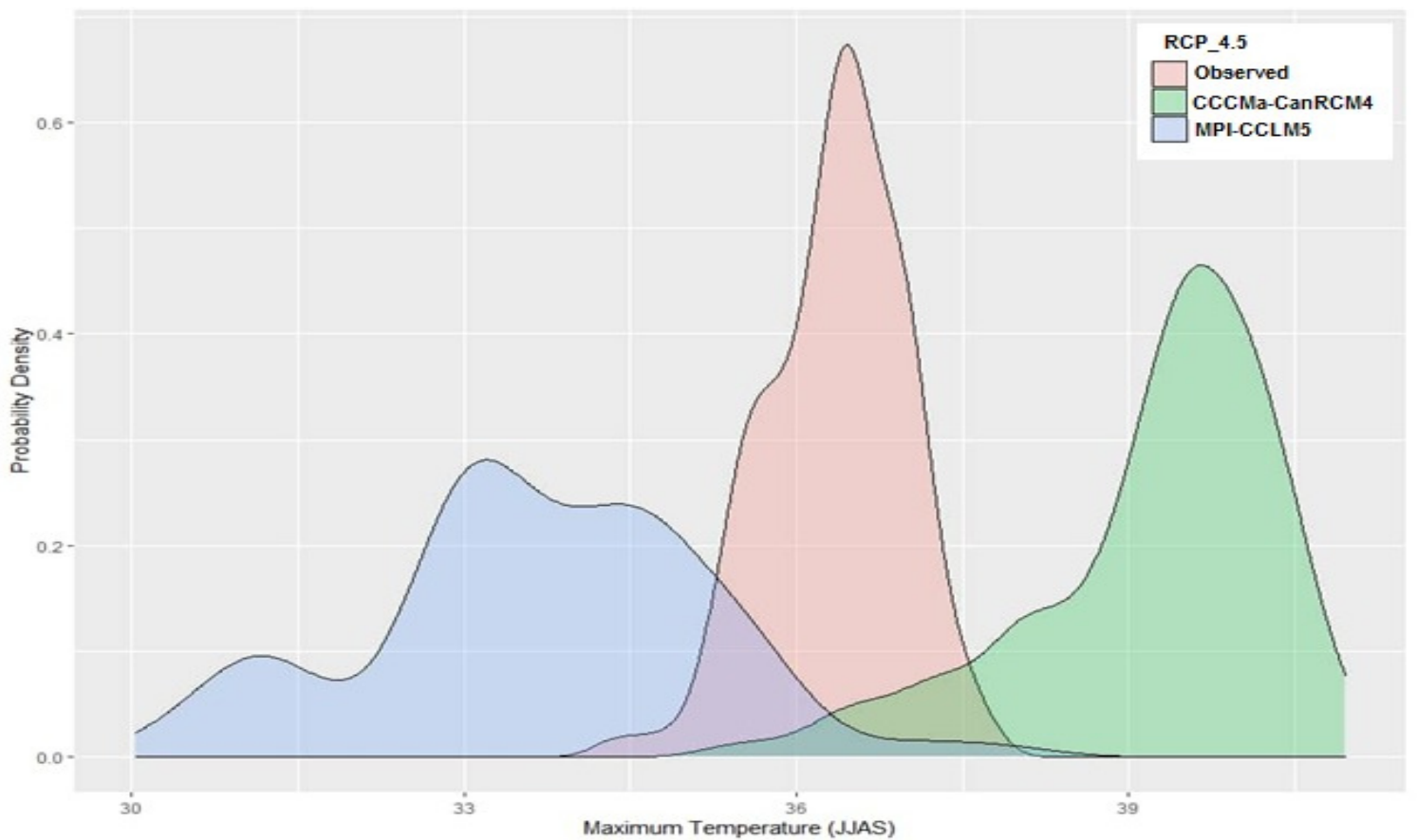

Figure 8: Probability Density Function of maximum temperature for Observed, CCCma-CanRCM4 and MPICCLM5 on RCP 4.5 in June, July, August and September over West Africa

Under the RCP 8.5 scenario (Figure 9), the models and observed PDF fairly agree at the distribution as the PDF tend to increase from 0.1 to 0.3 where CCCma-CanRCM4 model agreed with the observed and the MPICCLM5 model underestimated with the PDF value of 0.1 to 0.28 with maximum temperature range from $27^{\circ} \mathrm{C}$ to $35^{\circ} \mathrm{C}$ relatively low compared with CCCma-CanRCM4 and the observed from 1979 to 2018 in June, July, August and September from 1979-2018 over West Africa. The PDF yielded skill score for the maximum temperature revealed at 0.86 and 0.85 for CCCma-CanRCM4 and MPI-CCLM5 models respectively under RCP 8.5 scenario in June, July, August and September from 1979-2018 over West Africa (Figure 13).

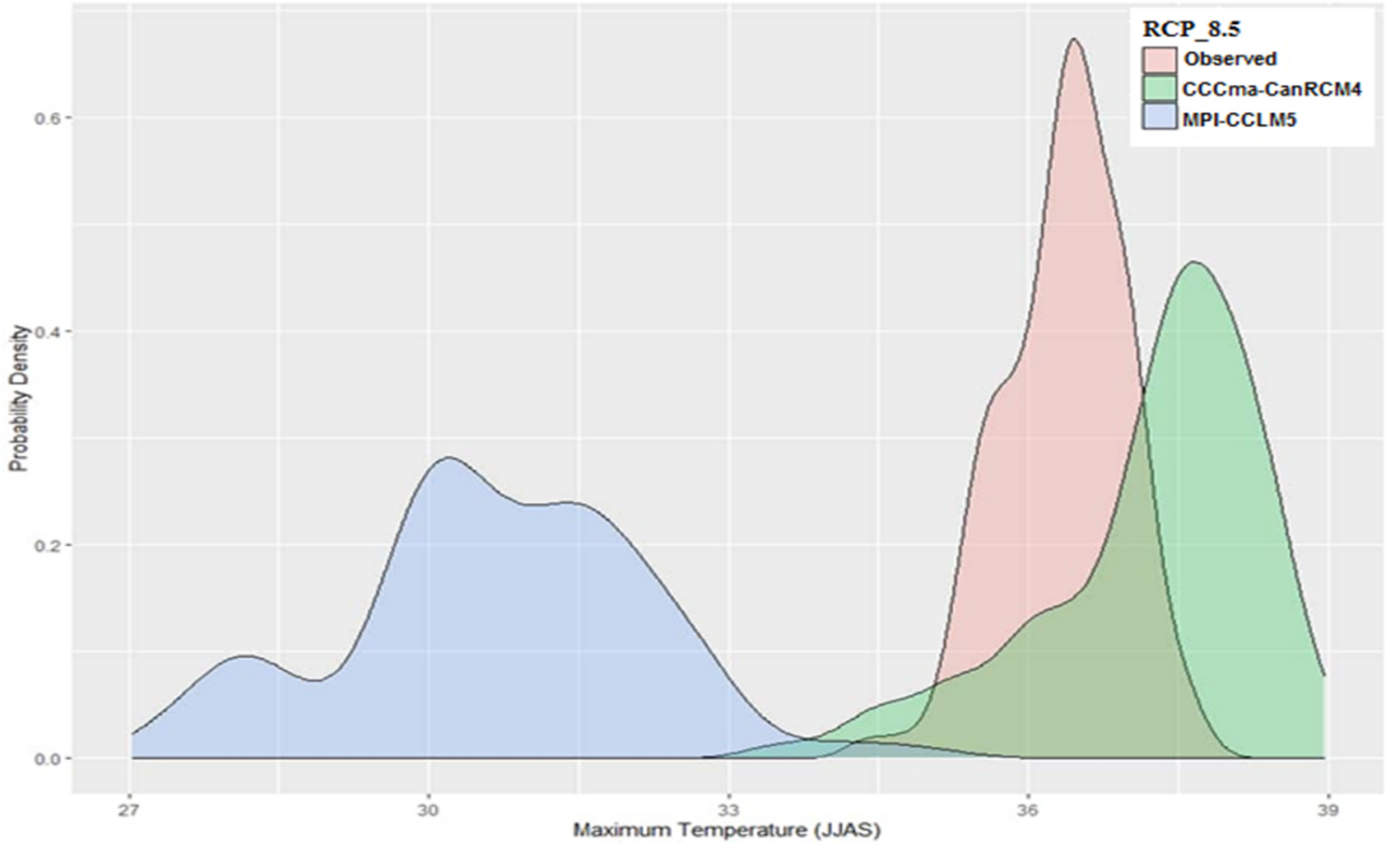

Figure 9: Probability Density Function of maximum temperature for Observed, CCCma-CanRCM4 and MPICCLM5 on RCP 8.5 in June, July, August and September over West Africa 

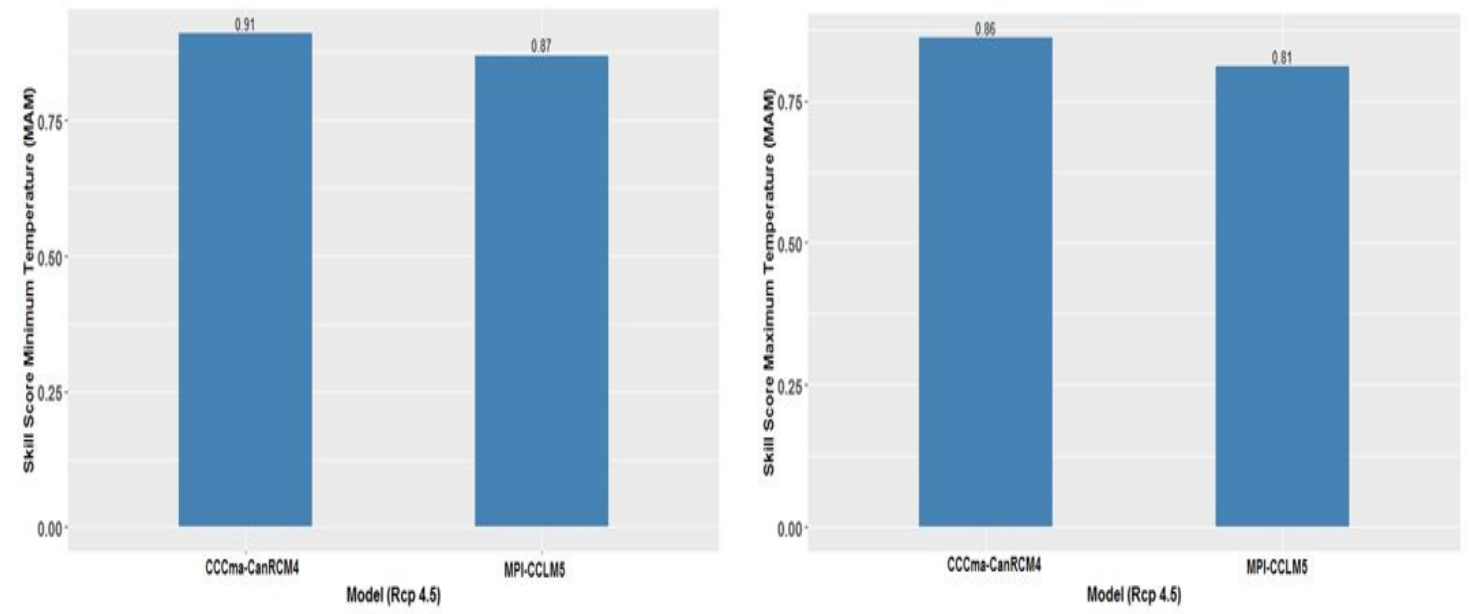

Figure 10: PDF-based skill score for the models for simulating minimum and maximum temperature for March, April and May under RCP 4.5.
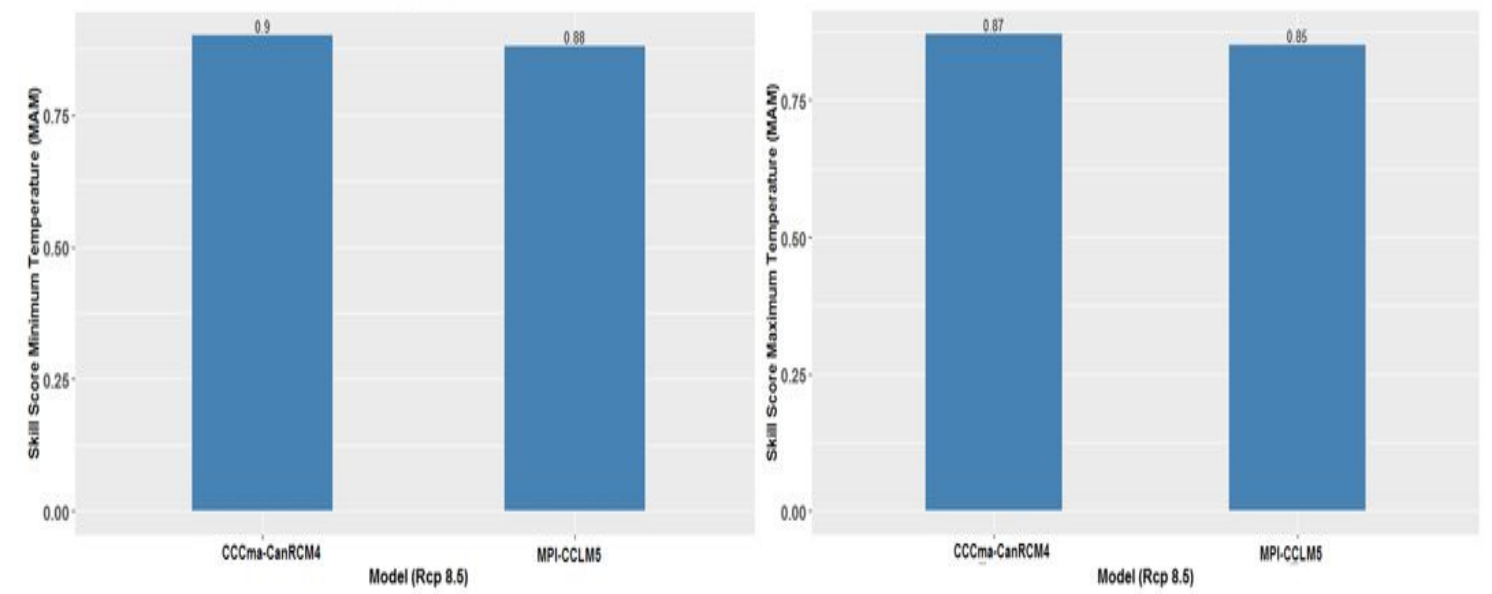

Figure 11: PDF-based skill score for the models for simulating minimum and maximum temperature for March, April and May under RCP 8.5.
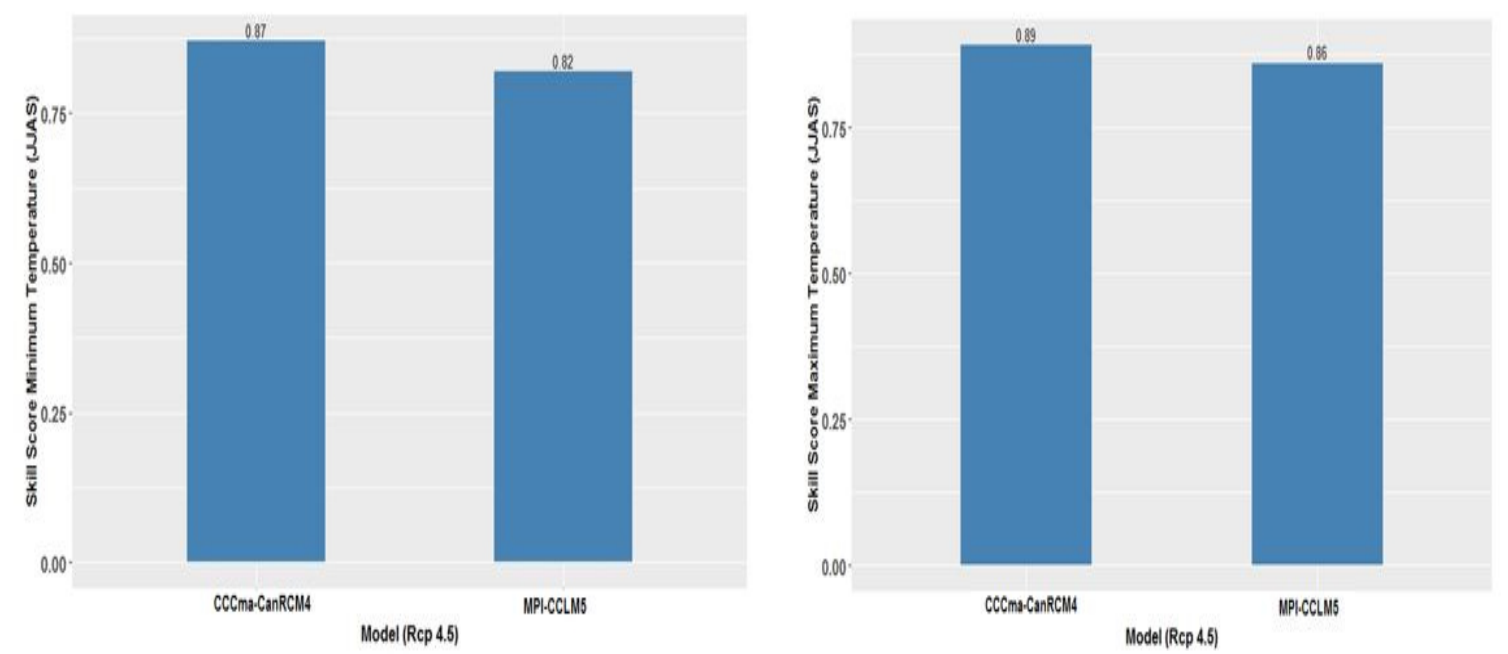

Figure 12: PDF-based skill score for the models for simulating minimum and maximum temperature for June, July, August and September under RCP 4.5. 

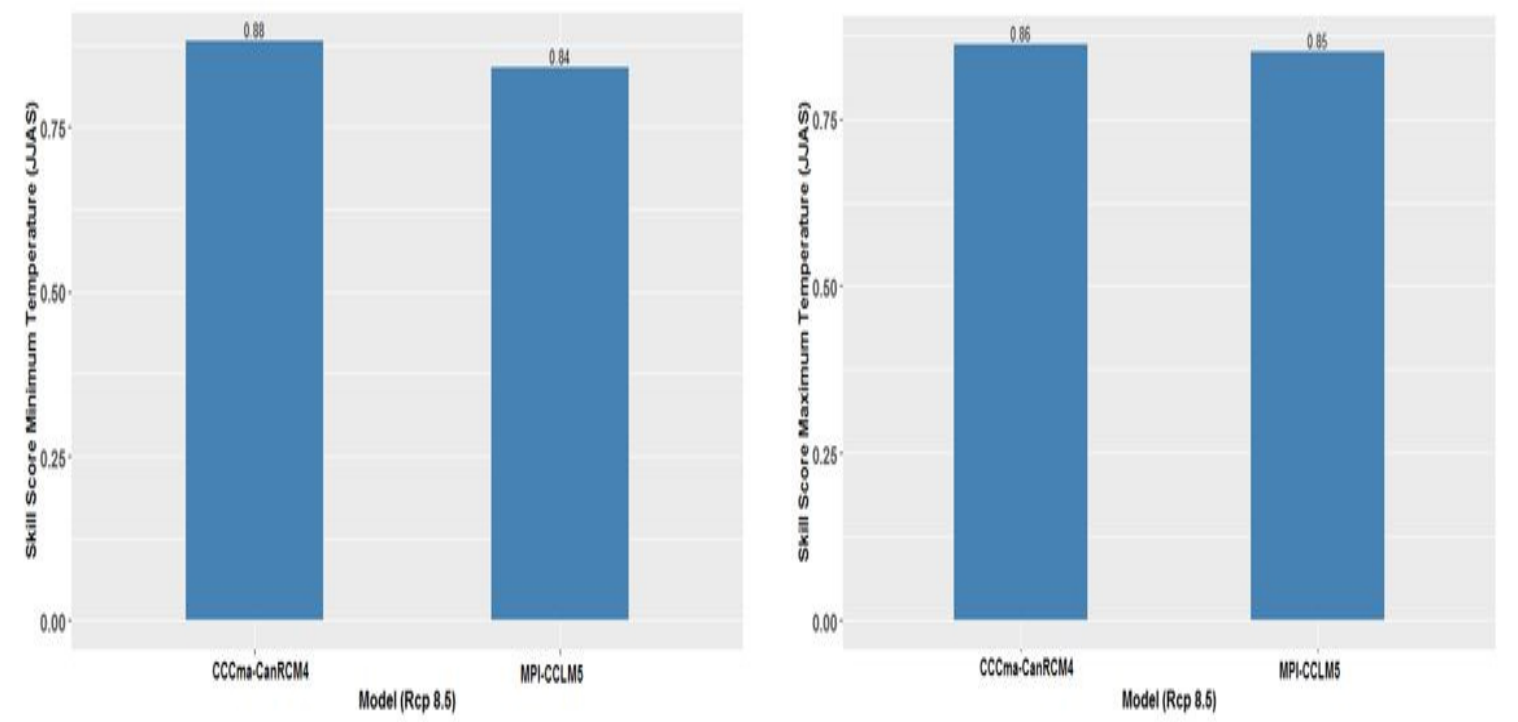

Figure 13: PDF-based skill score for the models for simulating minimum and maximum temperature for June, July, August and September under RCP 8.5.

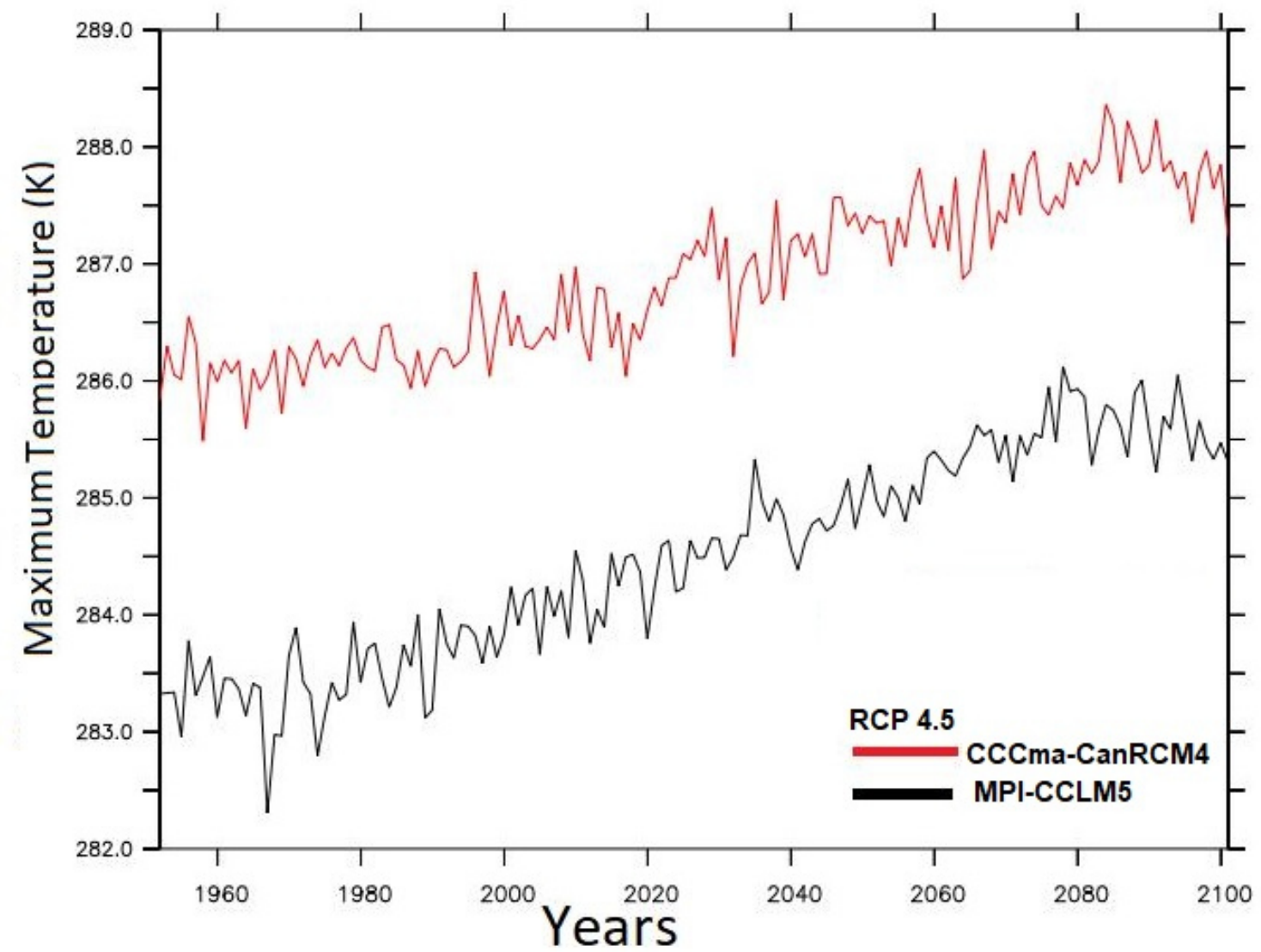

Figure 14: Maximum temperature for CCCma-CanRCM4 and MPI-CCLM5 under RCP 4.5 over West Africa 


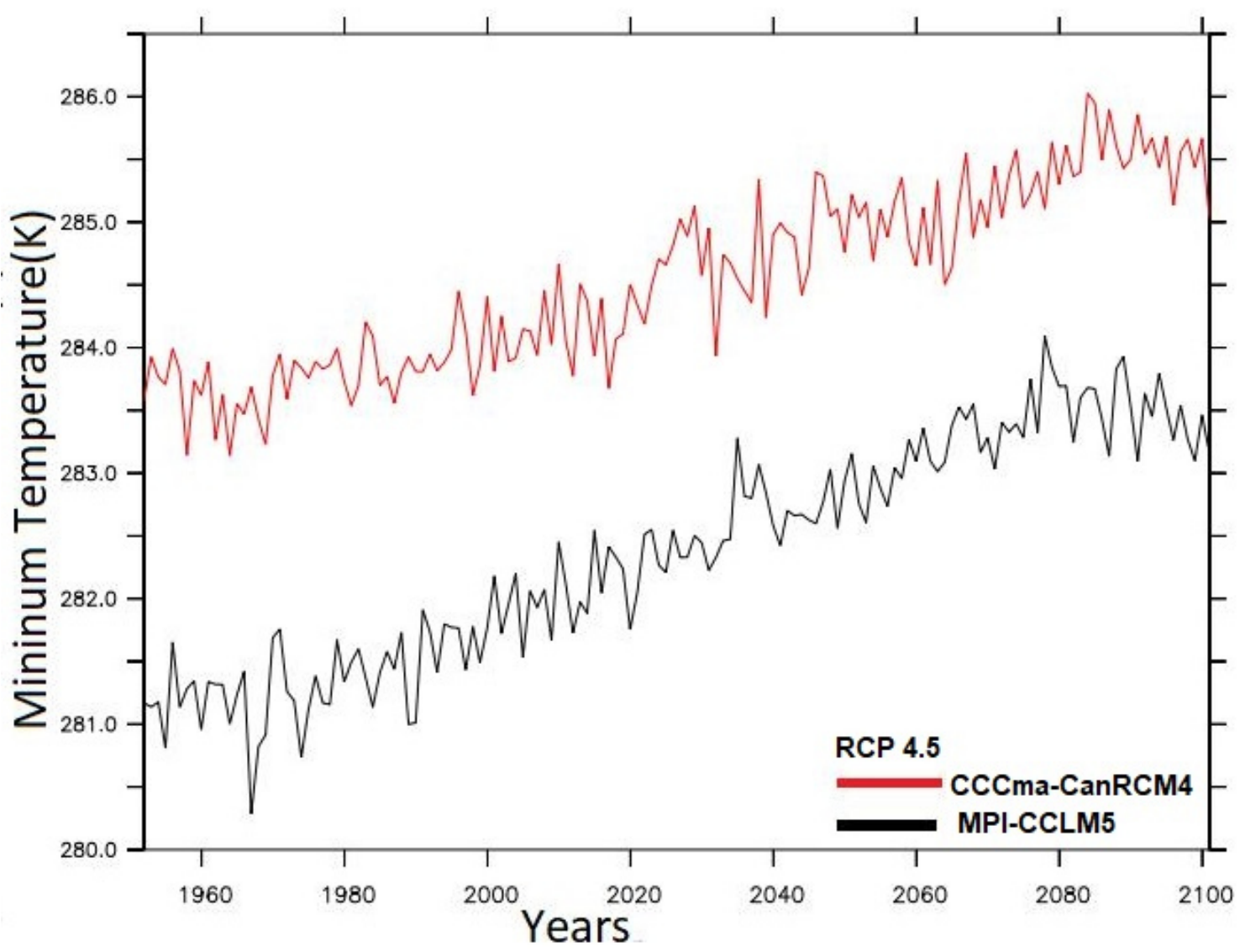

Figure 15: Minimum temperature for CCCma-CanRCM4 and MPI-CCLM5 under RCP 4.5 over West Africa

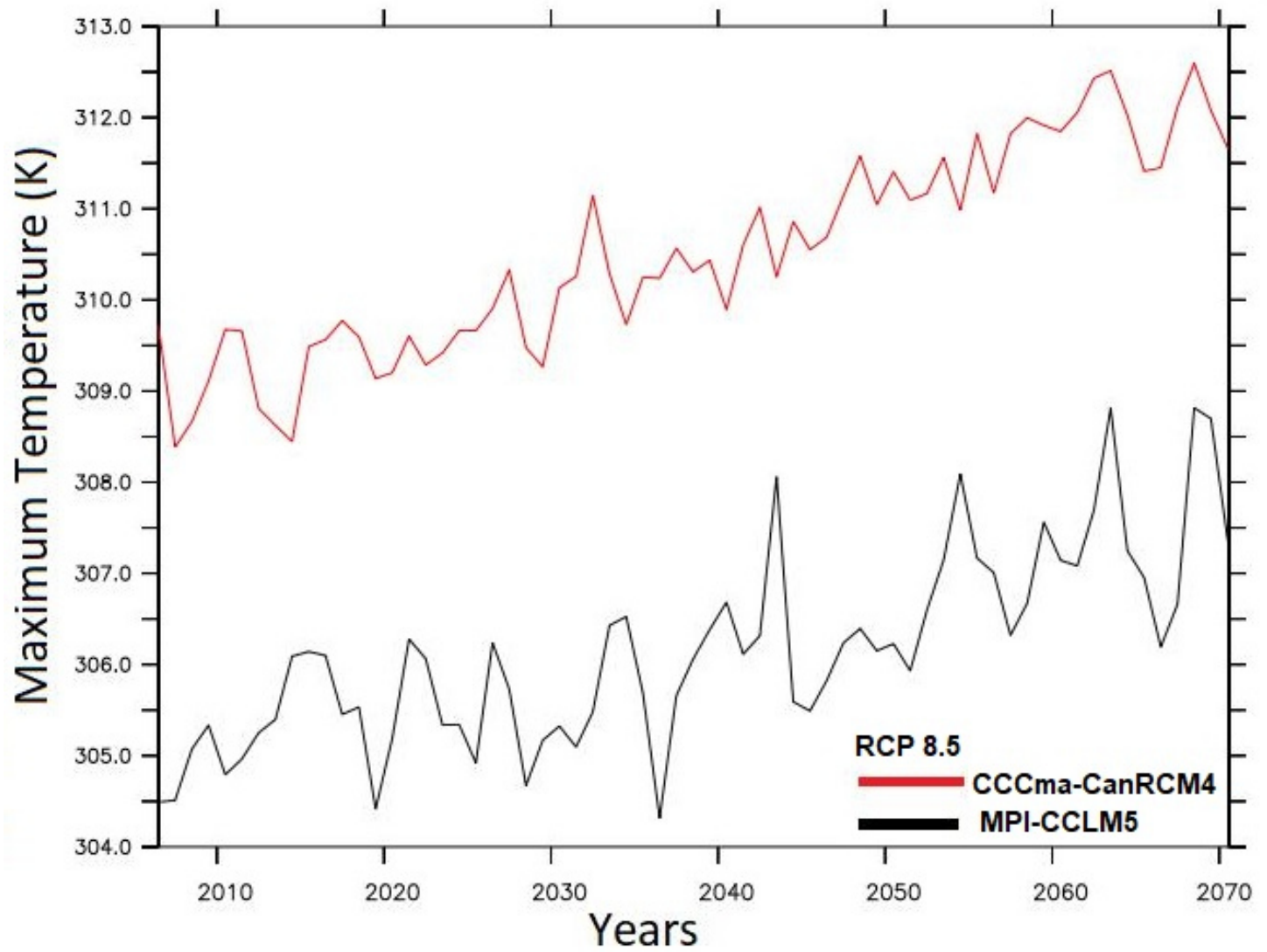

Figure 16: Maximum temperature for CCCma-CanRCM4 and MPI-CCLM5 under RCP 8.5 over West Africa 


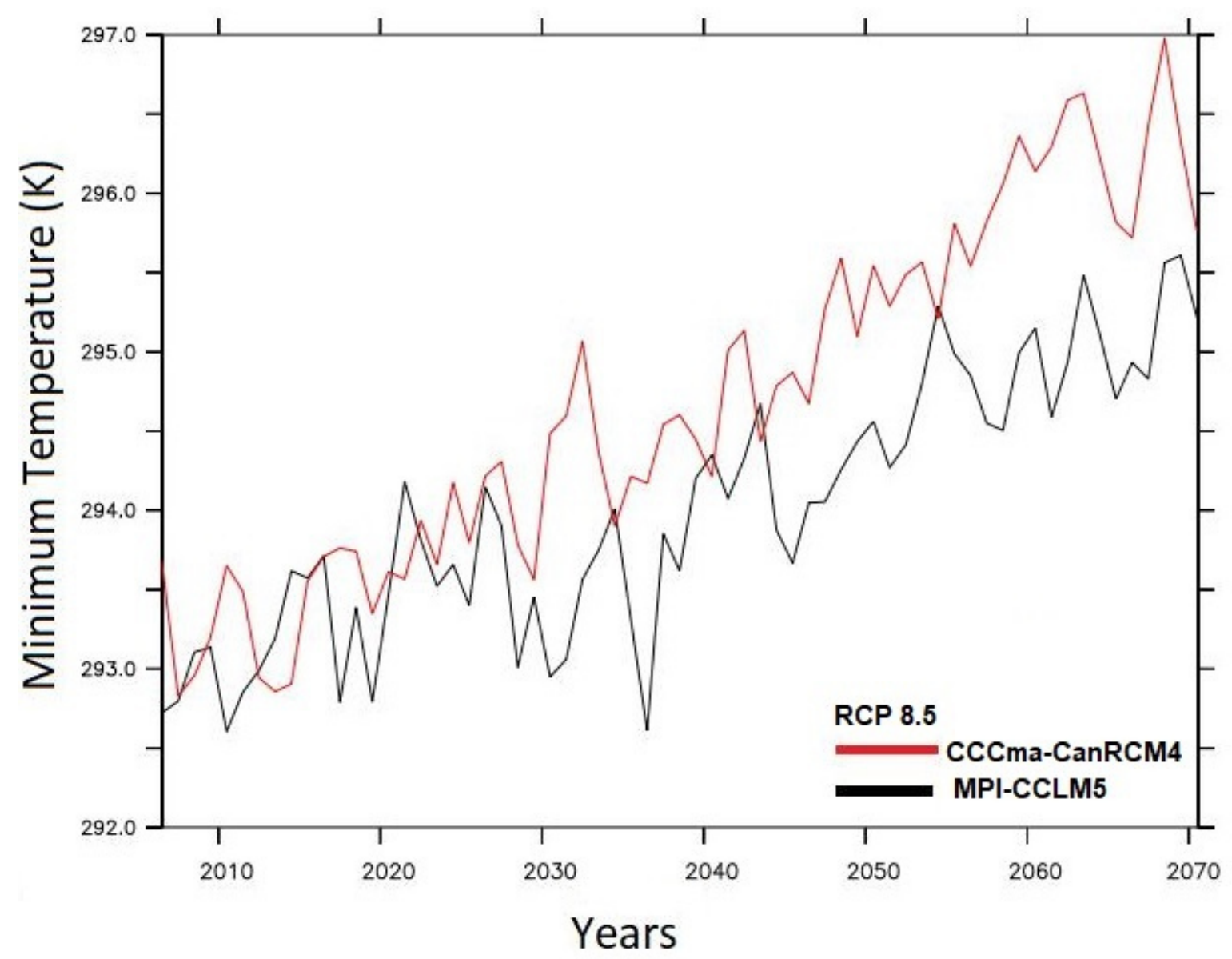

Figure 17: Minimum temperature for CCCma-CanRCM4 and MPI-CCLM5 under RCP 8.5 over West Africa

There is an evident warming trend as shown on (Figure 14-17) for CCCma-CanRCM4 and MPI-CCLM5 under RCP 4.5 and RCP 8.5 scenarios over West Africa. CCCma-CanRCM4 model projections under RCP 4.5 and RCP 8.5 was on the high side progressively above MPI-CCLM5 model, although both models revealed warming temperature conditions over West Africa which is in agreement with the report of Intergovernmental Panel on Climate Change (IPCC) working Group I (2021) of code red for humanity as the internationally agreed threshold of $1.5^{\circ} \mathrm{C}$ is perilously close.

\section{Conclusion}

The results from the study under RCP 4.5 and RCP 8.5 scenarios revealed an increasing temperature pattern with the observed, CCCma-CanRCM4 and MPI-CCLM5 in agreement, pointing towards a possible warmer climate over West Africa and this condition will negatively impact agricultural productivity, health and socio-economic activities over the region. This calls for possible climate adaptation and mitigation for a sustainable future to avoid migration and heightening on insecurity over West Africa.

\section{References}

Alexander LV, Zhang X, Peterson TC, Caesar J, Gleason B, Klein Tank aMG, Haylock M, Collins D, Trewin B, Rahimzadeh F, Tagipour A, Rupa Kumar K, Revadekar J, Griffiths G, Vincent L, Stephenson DB, Burn J, Aguilar E, Brunet M, Taylor M, New M, Zhai P, Rusticucci M, Vazquez-Aguirre JL (2006). Global observed changes in daily climate extremes of temperature and precipitation. J Geophys Res 111(D5):D05,109. doi:10.1029/2005JD006290

Chiew, F.H.S., Kirono, D.G.C., Kent, D. and Vaze, J. (2009). Assessment of rainfallsimulations from global climate models and implications for climate change impact on runoff studies. 18th World IMACS / MODSIM Congress, Cairns, Australia. http://mssanz.org.au/modsim09. (Last accessed 26/06/2013).

Collins, W. D. and Coauthors. (2006). The Community Climate System Model Version 3(CCSM3). Journal of Climate 19: 2122-2143.

Delworth, D., Boyle, C. and Li, R. (2006). GFDL's CM2 global coupled climate models. Part1: Formulation and simulation characteristics. Journal of Climate 19:643-674.

Dessai, S., Lu, X. and Hulme, M. (2005). Limited sensitivity analysis of regional climate change probabilities for 
the 21 st century. Journal of Geophysical Research 110: D19108. doi:10.1029/2005JD005919.

Fontaine B, Janicot S, Monerie PA (2013). Recent changes in air temperature, heat waves occurrences, and atmospheric circulation in Northern Africa. J Geophys Res Atmos 118:8536-8552. doi:10.1002/jgrd.50667

IPCC (2021). Summary for Policymakers. In: Climate Change 2021: The Physical Science Basis.

Contribution of Working Group I to the Sixth Assessment Report of the Intergovernmental Panel on Climate Change [Masson-Delmontte, V., P. Zhai, A. Pirani, S. L., Connors, C. Pean, S. Berger, N. Caud, Y. Chen, L. O. Yelekci, R. Yu and B. Zhou (eds.)]. Cambridge University Press. In Press.

IPCC (2012). Managing the risks of extreme events and disasters to advance climate change adaptation.

Johns, T. C. and Coauthors. (2006). The New Hadley Centre Climate Model (HadGEM1): Evaluation of coupled simulations. Journal of Climate 19: 1327-1353.

Knutti, R., Meehl, G. A., Allen, M. R. and Stainforth, D. A. (2006). Constraining climate sensitivity from the seasonal cycle in surface temperature. Journal of Climate 19: 4224-4233.

Milard, S.P (2013). EnvStats - An R Package for Environmental Statistics, XVI, 291 p.59-69.

Mitchell, T.D. (2003). Pattern scaling. Climatic Change 60: 217-242.

Murphy, J. M., Sexton, D. M. H., Barnett, D. N., Jones, G. S., Webb, M. J., Collins, M. AndStainforth, D. A. (2004). Quantification of modeling uncertainties in a large ensemble of climate change simulations. Nature 430: 768-772

New M, Hewitson B, Stephenson DB, Tsiga A, Kruger A, Manhique A, Gomez B, Coelho CaS, Masisi DN, Kululanga E, Mbambalala E, Adesina F, Saleh H, Kanyanga J, Adosi J, Bulane L, Fortunata L, Mdoka ML, Lajoie R (2006). Evidence of trends in daily climate extremes over southern and west Africa. J Geophys Res 111(D14):D14,102. doi:10.1029/2005JD006289

Nikulin G, Jones C, Giorgi F, Asrar G, Büchner M, Cerezo-Mota R, Christensen OB, Déqué M, Fernandez J, Hänsler A, van Meijgaard E (2012). Precipitation climatology in an ensemble

of CORDEX-Africa regional climate simulations. J Clim 25(18):6057-6078. https ://doi.org/10.1175/JCLI-D-1100375.1

Orlowsky B, Seneviratne SI (2011). Global changes in extreme events: regional and seasonal dimension. Clim Change 110(3-4):669- 696. doi:10.1007/s10584-011-0122-9

Ramirez-Villegas J., Challinor, A. J., Thornton, P. K. and Jarvis, A. (2013). Implications ofregional improvement in global climate models for agricultural impact research. Environmental Research Letters 8024018. doi:10.1088/1748-9326/8/2/024018.

Scinocca et al. (2016). Coordinated Global and Regional Climate Modeling. Journal of Climate 29, 1; pgs.1735, 10.1175/JCLI-D-15-0161.1

Siegert, S., J. Bhend, I. Kroener and M. de Felice (2017). Package "SpecsVerification": Forecast verification routines for ensemble forecast of weather and climate. R-project, 44 pp., https://cran.rproject.org/web/packages/SpecsVerification/SpecsVerification.pdf.

Sillmann J, Kharin VV, Zhang X, Zwiers FW, Bronaugh D (2013a). Climate extremes indices in the CMIP5 multimodel ensemble: part 1. Model evaluation in the present climate. J Geophys Res Atmos 118(4):17161733. doi:10.1002/jgrd.50203

Sillmann J, Kharin VV, Zwiers FW, Zhang X, Bronaugh D (2013b). Climate extremes indices in the CMIP5 multimodel ensemble: part 2. Future climate projections. J Geophys Res Atmos 118(6):2473-2493. doi:10.1002/jgrd.50188

Tebaldi C, Hayhoe K, Arblaster JM, Ga Meehl (2006). Going to the extremes. Clim Change 79(3-4):185-211. doi:10.1007/ s10584-006-9051-4

Watterson, I. G. (1996). Non-dimensional measures of climate model performance. International Journal of Climatology 16: 379-391. 